\title{
Snow fence load on a house roof with tiles
}

\author{
Cornel Cătălin GAVRILA ${ }^{1}$ and Mihai -Tiberiu LATEŞ ${ }^{2}$ \\ ${ }^{1}$ Transilvania University of Brasov, Romania \\ ${ }^{2}$ Transilvania University of Brasov, Romania
}

\begin{abstract}
Virtual modeling of mechanical structures, using computer performant software, is largely used in many fields. The paper presents some aspects regarding the loads on a snow fence mountig system, placed on a house roof with ceramic tiles. First, there are presented some general aspects of the snow fence types and mounting systems used. Then, there are Then there are presented the aspects about virtual modeling of these parts, using CATIA software. Also, there are presented some aspects about the Finite Element Analysis, respectively the results of this. In the paper final part, there are presented the conclusion.
\end{abstract}

\section{Introduction}

The virtual modelling, the detail design and also the FEM analysis of mechanical products, using computer software is a necessity and it saves time in product developing, reduces the number of physical prototypes and experiments, reduces the prices of product and also, increases the quality of product. In the paper there are presented some aspects regarding the virtual modelling and FEM analysis for a snow fence mounting system fixed on a house roof.

Generally, to prevent the snow fall from buildings, there are available many constructive solutions. Usually, the producers providing the adequate fixing kit for snow fence, but the solutions are related more to the new types of tiles used than the previously manufactured. For old roofs types, the kits provided are not matching very well as dimensions or are not manufactured as well. This mismatching lead usually to the early roof damages, snow falling, or water drip inside the construction. The ceramic tiles produced and used in Romania are standardized according to SR EN 1304 + A1: 2001 [1] (the former Romanian STAS 515 - Ceramic Tiles and Ridges).

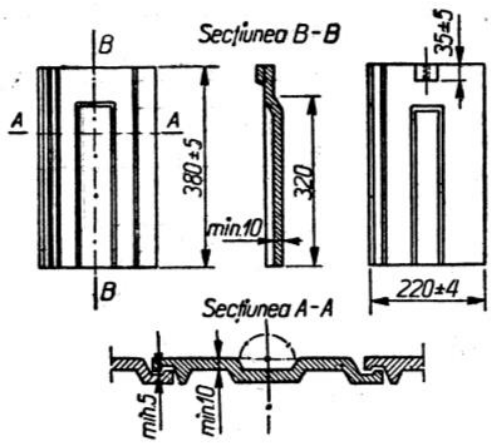

Fig. 1. The tile main dimensions.
According to the standard, for the big format tiles with drains and shafts with one lateral rib and one nose, the main dimensional characteristics are presented in Fig. 1. It is the most used tile type in Romania's last 60 years until today. This type of tiles can be arranged only in network (Fig. 2) on the roof structure made by thin wide woods placed on wood timbers. In this case, the wide woods distance is $33,5 \mathrm{~mm}$ [3].

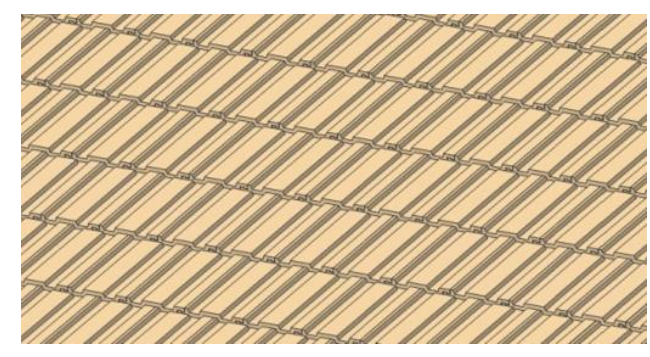

Fig. 2. The tiles arrangement on roof

The most used constructive solution for snow fence mounting system consist in metal folded clips inserted between the tiles and fixed on roof wood structure, as is presented in Fig. 3, a, and b [2].

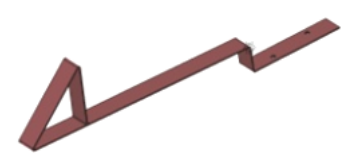

a.Snow fence folded clip

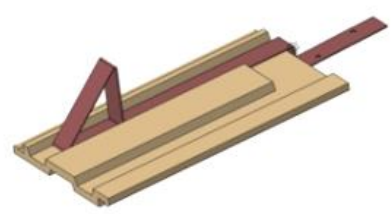

b. The clip placed on tile

Fig. 3. The snow fence clip and the tile

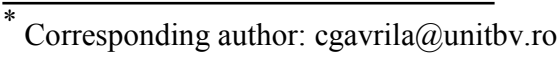




\section{The Snow Load on Roof}

According to "Technical regulation CR 1-1-3/2012 [3]", the snow load on roof depends by a lot of factors, as the thickness of the snow layer, roof shape and declination and, also, the snow distribution by wind and snow melting. When the snow layer slides on roof, the snow fence, considered as obstacle, is loaded with a force on length unit, given by relation

$$
F_{\mathrm{s}}=s b \sin \alpha_{\mathrm{r}},
$$

where

$s$ - the characteristic snow load on roof, in $\mathrm{kN} / \mathrm{m}^{2}$

$b$ - the horizontal distance between snow fence clips, in $\mathrm{m}$

$\alpha_{\mathrm{r}}-$ the roof declination, in degrees.

The characteristic snow load on roof can be calculated by relation

$$
\mathrm{s}=g_{\mathrm{IS}} \mu_{\mathrm{i}} S_{\mathrm{k}},
$$

where

$g_{\text {IS }}-$ the exposing at snow load factor

$\mu_{\mathrm{i}}$ - the shape factor of snow load on roof

$s_{\mathrm{k}}$ - the snow load on the ground, in $\mathrm{kN} / \mathrm{m}^{2}$.

The studied snow fence mounting system is considered placed on a building roof, with two sides, both declined at 30 degrees by horizontal reference. The building priority class is III. According to the mentioned technical regulations, the shape factor value is $\mu_{\mathrm{i}}=0.8$, for the considered case.

The snow load on the ground is $s_{\mathrm{k}}=2 \mathrm{kN} / \mathrm{m}^{2}$, a standard value given for Brasov location.

Because the snow fence clips are usually fixed on the roof wood timbers, the horizontal distance between them may vary between 0,8 and $1 \mathrm{~m}$ (fig. 4). An increased distance lead to premature bending for thin wide woods just under the tiles weight. Also, a shorter distance is not used.

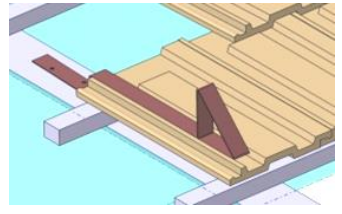

a.Fixed on wood timber

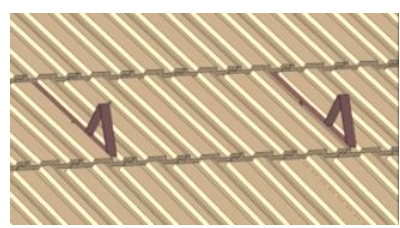

b. The horizontal distance
Fig. 4. The snow fence clip on the tiles

Taking account by relations (1) and (2), the resulted force along the roof declination, on a snow fence clip is $800 \mathrm{~N}$, for considered horizontal distance value $\mathrm{b}=1 \mathrm{~m}$. If the considered horizontal distance value is reduced to $b$ $=0,8 \mathrm{~m}$, the force decrease to $640 \mathrm{~N}$.

\section{The Virtual Modelling}

The virtual model is developed, using CATIA software, for the metallic clip and the ceramic tile, as the main parts involved in snow fence fixing operation on the roof $[4,5]$. The wood roof structure, which serves to support the entire assembly, is considered as rigid.
For metallic snow fence clip, first step is to sketch the main section. The dimension are given by producer, but, to fit the clip in the roof structure, it has to be considered the difference angle between the declinations, previously introduced [6]. For the studied case, the difference angle between the declinations is $\alpha_{d}=2$ degrees. Then, using Part Design module, the virtual model is completed, as is presented in Fig. 3, a.

For the tile, first step is to sketch the main section, with drains and shafts and one lateral rib and one nose. Then, using Part Design module, the virtual model is completed, as is presented in Fig. 5.

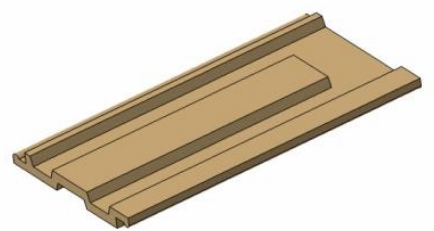

a.The tile top view

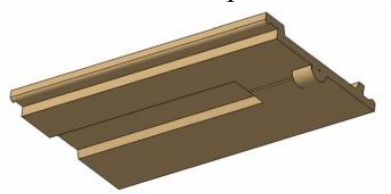

b. The tile bottom view

Fig. 5. The tile virtual model

To assembly the components, the Assembly Design module is used. The assembled virtual model was already presented in Fig. 3, b, for the snow fence clip and tile, in Fig. 4, a, for clip fixed on the timber wood, and, respectively, in Fig. 4, b, for the entire roof ensemble.

Because of the tile shape, with drains and shafts, the metalic clip may be placed in few particular positions, as it is presented in Fig. 6, a - c.

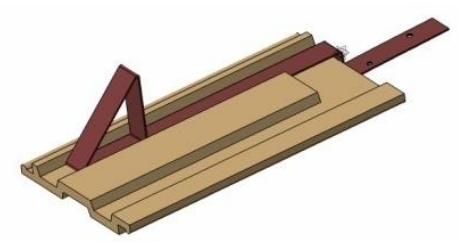

a. The left position

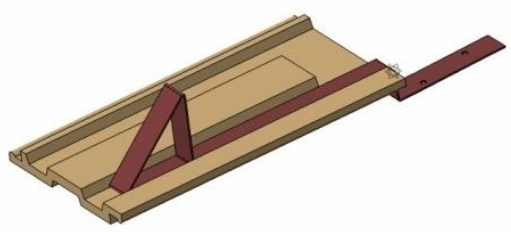

b. The right position

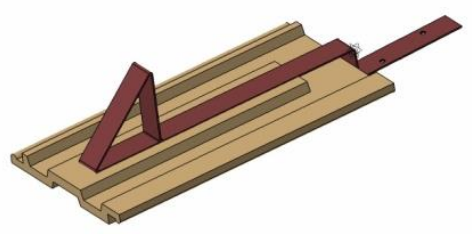

b. The middle position

Fig. 6. The snow fence clip particular positions 
In the Fig. 6, a, the snow fence clip is placed in the tile left drain. In the Fig. 6, b, the snow fence clip is placed in the tile right drain. Also, in the Fig. 6, c, the clip is placed on the tile middle width sector.

\section{The Finite Element Analysis}

For analysis, the previous models for snow fence metalic clip and for the tile will be used. The material properties, as Young modulus, Poisson coefficient, Tensile Yield Strength, Ultimate Strength should be defined.

For snow fence metalic clip, the used material is steel $[6,7]$. For the analysis, the loading force, $F_{\mathrm{s}}$ is applied along the roof declination corresponding to a tile declined at 30 degrees by horizontal reference. For simulation, the metalic clip is considered fixed on the surface asembled on timber wood and, respectively, on the bottom sector, where it loads the tile. To estimate the deformations, the metalic clip will be also considered with no tile above. The model needs to be meshed into finite elements, solids and deformable, type hexaedral and tetraedral, with integration node [7]. The metallic clip model, with defined force, is presented in Fig. 7.

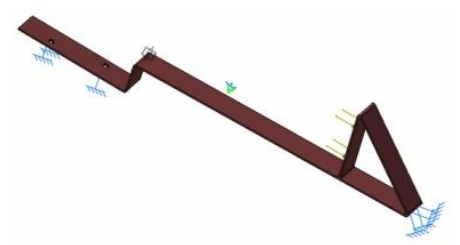

Fig. 7. The snow fence metalic clip with defined force

For the tiles, the material is ceramic, with the main properties given by literature $[8,9]$. The ceramic materials are fragile - under the load, are subjected to break before some elastic deformations. Also, the ceramic materials present the static fatigue - for an increased time of load application, the break resistance is decreasing. For analyse, the ceramic material for tiles is considered having fine texture: homogenous granulation, without material failures, as breaks or inclusions. For ceramic material, the limit stress is $15 \mathrm{MPa}$.

The tile model also needs to be meshed into finite elements, solids and deformable, type hexaedral and tetraedral, with integration node. The tile is declined at 28 degrees by horizontal reference, and the resultant force is applied on a contact surface with the bottom sector of the snow fence clip. The tile is considered fixed above the nose, on the line contact and on the bottom edges, which correspond to the placing on the tiles above. The tile model with defined force is presented in Fig. 8.

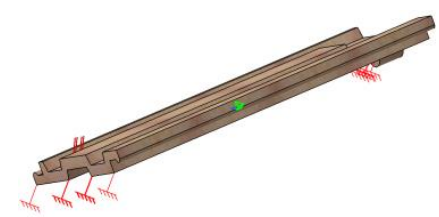

Fig. 8. The tile model with defined force

\section{The Simulations and Results}

The snow fence metalic clip simulation was made for both cases of load:

- $F_{\mathrm{s}}=640 \mathrm{~N}$, for horizontal distance $\mathrm{b}=0,8 \mathrm{~m}$,

$-F_{\mathrm{s}}=800 \mathrm{~N}$, for horizontal distance $\mathrm{b}=1 \mathrm{~m}$.

In Fig. 9 there are presented the snow fence metalic clip deformations and it can be observed that, the maximum deformation value appear on the top folded sector.

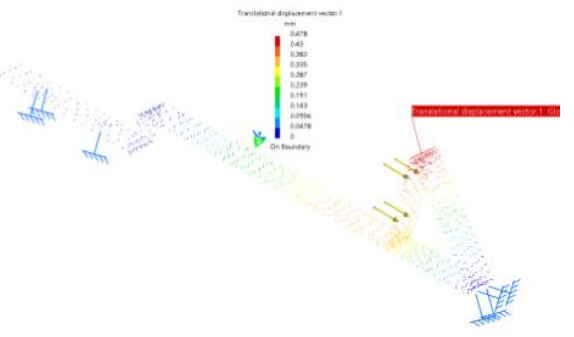

Fig. 9. The deformations on the snow fence metalic clip

In Fig. 10 is presented the stress on the metalic clip; the maximum value is $123 \mathrm{MPa}$, and appears on the bottom end, where the clip is folded.

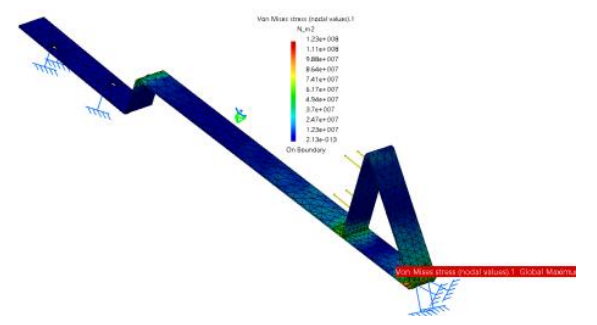

Fig. 10. The stress on the snow fence metalic clip

The snow fence metallic clip simulation results are presented in Table 1.

Table 1. The simulation results for snow fence metallic clip.

\begin{tabular}{|c|c|c|c|}
\hline $\begin{array}{c}\text { Horizontal } \\
\text { distance, } \mathrm{m}\end{array}$ & $\begin{array}{c}\text { Load force, } \\
\mathrm{N}\end{array}$ & $\begin{array}{c}\text { Maximum } \\
\text { deformation, } \\
\mathrm{mm}\end{array}$ & $\begin{array}{c}\text { Maximum } \\
\text { stress, MPa }\end{array}$ \\
\hline 0,8 & 640 & 0,382 & 98,8 \\
\hline 1 & 800 & 0,478 & 123 \\
\hline
\end{tabular}

For the tile simulation, there are considered the each snow fence metallic clip positions on tile, presented in Fig. 6, a - c. The load on tile is applied distributed on the contact area with bottom end of the snow fence metalic clip. Because this contact area may vary, depending by the tile and clip folding radius and also by positioning on roof structure, there is considered the reduced contact area to $33 \times 5 \mathrm{~mm}$, which correspond to increased misalignments and increased snow fence clip deformations.

The tile simulation was also made for both cases of load force, previously presented. 


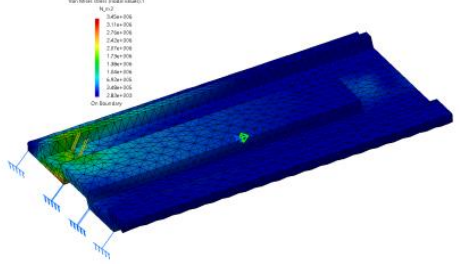

a. Stress values for the load applied on the left position

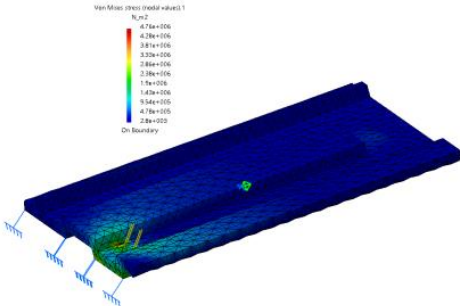

b. Stress values for the load applied on the right position

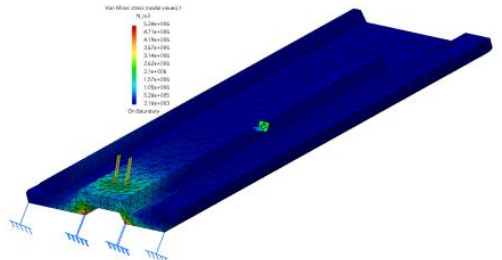

c. Stress values for the load applied on the middle position

Fig. 11. Stress values on tile

In Fig. 11, the obtained stress maximum values on tile is presented. The tile simulation results are presented in Table 2.

Table 2. The simulation results for tile.

\begin{tabular}{|c|c|c|c|}
\hline $\begin{array}{c}\text { The load } \\
\text { position }\end{array}$ & $\begin{array}{c}\text { Horizontal } \\
\text { distance, } \mathrm{m}\end{array}$ & $\begin{array}{c}\text { Load force, } \\
\mathrm{N}\end{array}$ & $\begin{array}{c}\text { Maximum } \\
\text { stress, MPa }\end{array}$ \\
\hline \multirow{2}{*}{ Left } & 0,8 & 640 & 2,76 \\
\cline { 2 - 4 } & 1 & 800 & 3,45 \\
\hline \multirow{2}{*}{ Right } & 0,8 & 640 & 3,8 \\
\cline { 2 - 4 } & 1 & 800 & 4,76 \\
\hline \multirow{2}{*}{ Center } & 0,8 & 640 & 4,19 \\
\cline { 2 - 4 } & 1 & 800 & 5,24 \\
\hline
\end{tabular}

\section{Conclusions}

On real snow fence device assembly, there are situations when, because of surfaces misalignments, the contact surface between the studied parts may be different from the studied case.

For metallic clip, the deformations and stresses values are lower than the limit values recommended in literature for steel. But, the clip bending is possible, when the load accidentally increases.
For tiles, in all the studied cases, the maximum stress values are lower than the limit values recommended in literature for ceramic materials, so the tile resist to load. Comparative, from all three cases of tile load, the lowest values were obtained for the snow fence position as in Fig. 6 , a; respectively the maximum values were obtained for the center position, as in Fig. 6, c.

Taking account that the ceramic materials are fragile and present the static fatigue - for an increased time of load application, the break resistance is decreasing in subjected locations.

To prevent the roof failures because of the snow load (the tile breaking or the metalic clip bending), the snow fence clips must be placed on the roof at prescribed distance and arrangement.

For other locations, the calculus and simulation is similar.

\section{References}

1. Romanian Standard, SR EN $1304+$ A1: 2001, Ceramic Tiles and Ridges, 2001.

2. https://www.accesoriipentruacoperis.ro/parazapezi/

3. Technical regulation CR 1-1-3/2012, Design Code: Snow Action On Construction Evaluation (Cod de proiectare. Evaluarea actiunii zapezii asupra constructiilor), 2012 (in romanian).

4. C. Alexandru, Mechanical Articulated Systems Simulation on Computer (Simularea pe calculator a sistemelor mecanice articulate), Ed. Lux Libris, Braşov, 2000 (in romanian).

5. I.G. Ghionea, CATIA v5. Application in Mechanical Engineering (CATIA v5. Aplicaţii in ingineria mecanică), Editura Bren, București, 2009 (in romanian).

6. C. C. Gavrilă, R. Velicu, M. T. Lateş, 3D Modeling and FEM Analysis for Solar Panel Mounting System on a House Roof, In: Annals of the Oradea University, Fascicle of Management and Technological Engineering, Volume XVI, (XXVI), Oradea 2017, pp. $1-4$.

7. M. T. Lateş, R. Velicu, R. Papuc, Multiscale modelling of chain-guide contact by using tests and FEM. 11th World Congress on Computational Mechanics WCCM XI, Barcelona, Spain, 20-25 July, 2014, pp.1062-1069.

8. C. Bob, P. Velica, Construction Materials (Materiale de construcţii), Ed. Didactică şi Pedagogică, Bucureşti, 1978 (in romanian).

9. I. Teoreanu, N. Ciocea, A. Bărbulescu, N. Ciontea, Ceramic and Refractory Material Technology (Tehnologia produselor ceramice şi refractare), Vol. I, Ed. Tehnică, Bucureşti (in romanian). 